\title{
Lipopolysaccharide challenge significantly influences lipid metabolism and proteome of white adipose tissue in growing pigs
}

\author{
Jun Guo', Zhiqing Liu', Hailin Sun ${ }^{1}$, Yanping Huang ${ }^{1}$, Elke Albrecht ${ }^{2}$, Ruqian Zhao ${ }^{1}$ and Xiaojing Yang ${ }^{1 *}$
}

\begin{abstract}
Background: White adipose tissue is recognized as a highly active organ, which is closely related to a large number of physiological and metabolic processes besides storing triglycerides. However, little is known regarding the response of adipose tissue to acute inflammation. Therefore, in this study we employed growing pigs to investigate the changes of lipid metabolism and proteome in white adipose tissue after lipopolysaccharide (LPS) stimulation as a model for bacterial infection.
\end{abstract}

Methods: The expression of lipid metabolism and inflammation related genes was determined by quantitative real-time polymerase chain reaction. Label-free proteomics analysis was used to investigate changes of the protein profile in white adipose tissue and western blot was used to verify changes of selected adipokines.

Results: The results indicated that LPS significantly increased the expression of toll-like receptor (TLR) 2/4 pathway-related genes and pro-inflammatory factors. Lipid metabolism related genes, including acetyl-CoA carboxylase 1 (ACACA), fatty acid synthase (FASN), stearoyl-CoA desaturase (SCD), uncoupling protein 2 (UCP2), and $11 \beta$-hydroxysteroid dehydrogenase type 1 (11ß-HSD1), were down-regulated and the lipolytic enzyme activity was decreased after LPS injection. Proteome analysis revealed 47 distinct proteins with $>2$-fold changes. The down-regulation of two proteins (CAMP-dependent protein kinase type II-alpha regulatory subunit and $\beta$-tubulin) has been verified by western blot analysis. In addition, the abundance of two adipokines (adiponectin and zinc-a2-glycoprotein) was significantly increased after LPS injection.

Conclusion: In conclusion, LPS challenge can cause acute inflammation in white adipose tissue. Concurrently, lipid metabolism was significantly suppressed and the abundance of several proteins changed in white adipose tissue. The results provide new clues to understand the adipose dysfunction during inflammation.

Keywords: Acute inflammation, Lipid metabolism, Proteome, White adipose tissue, Pig

\section{Background}

In the traditional view, white adipose tissue (WAT) in mammals was seen as the main site for energy storage. However, this view changed since more and more studies demonstrated that WAT is not only a passive storage of triglycerides but also a highly dynamic organ which is closely related to a large number of physiological and metabolic processes [1]. WAT actively participates in body energy regulation through a network of endocrine,

\footnotetext{
* Correspondence: yangxj@njau.edu.cn

${ }^{1}$ Key Laboratory of Animal Physiology \& Biochemistry, Nanjing Agricultural University, Nanjing 210095, PR China

Full list of author information is available at the end of the article
}

paracrine and autocrine signals [2]. Recent researches suggest that adipocytes are also immunologically active, and may play an important role in host defense [3-5].

At present, humans and animals frequently suffer from inflammation, which can be induced by bacterial infection, especially by gram-negative bacteria [6]. Obesity, as one of the most serious health risks, is always associated with low-degree inflammation [7]. However, most of the investigations concerning inflammation focus on immunocytes or immune organs [8], only a minority of researchers pay attention to WAT in this regard [9-11]. In those studies, changes in the gene expression profile of human adipose tissue after acute inflammation were 
investigated $[9,11]$. It has been shown that even subacute inflammation induces signs of inflammation and changes in lipoprotein metabolism in the adipose tissue of cats [10]. Meanwhile, it has been demonstrated that fat depots are differently sensitive to lipopolysaccharide (LPS) stimulation as indicated by nuclear factor- $\mathrm{kB}$ (NF$\mathrm{\kappa B})$ activation [12]. LPS is the major component of the outer membrane in gram-negative bacteria [13] and it can cause acute inflammation resulting eventually in all kinds of pathophysiological damages [14]. LPS injection was used in the present study to simulate bacterial infection and to study inflammation-induced changes in lipid metabolism and in the proteome of WAT.

In recent years, following the rapid development of mass spectrometry, proteomics analysis has been frequently used as a very powerful bioanalytical method for solving various scientific problems from medicine, biology and biochemistry [15]. Especially, label-free proteomics analysis has emerged as a high-throughput method for quantitative clinical proteome studies. Therefore, label-free proteomics analysis was used in the present study to determine changes of the protein profile in WAT of growing pigs after LPS stimulation. Together with observed changes in lipid metabolism, the results may provide a promising clue to metabolic and inflammatory responses leading to the development of adipose tissue dysfunction.

\section{Results}

Expression of genes involved in toll-like receptor 2 and 4 pathway and inflammatory cytokines

As shown in Fig. 1, the gene expression of toll like receptor 2 (TLR2), TLR4, and NF- $\mathrm{B}$ p 65 were all significantly increased after LPS stimulation for 6 h. Similarly, the gene expression of inflammatory cytokines, such as tumor necrosis factor- $\alpha$ (TNF- $\alpha)$, interleukin- $1 \alpha$ (IL-1 $\alpha)$,

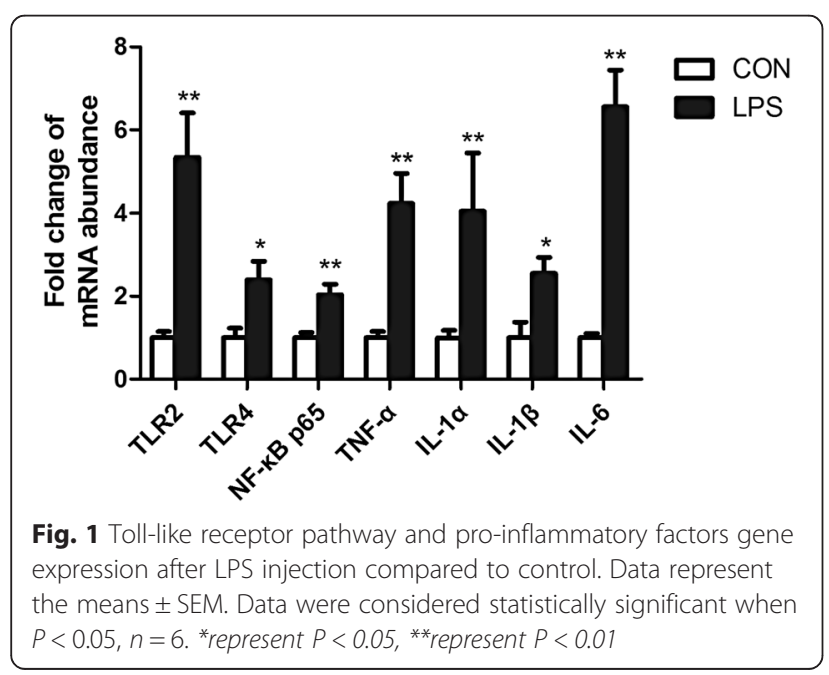

IL-1 $\beta$, and IL-6 was also higher $(P<0.05)$ in LPS stimulated animals compared to controls.

\section{Expression of genes involved in lipid metabolism}

As shown in Fig. 2, the gene expression of key enzymes of lipogenesis, including acetyl-CoA carboxylase 1 (ACACA), fatty acid synthase (FASN), and stearoyl-CoA desaturase (SCD), decreased after LPS treatment $(P<0.05)$. The gene expression of key enzymes of lipolysis, including hormone-sensitive lipase (HSL) and adipose triglyceride lipase (ATGL), remained unchanged $(P>0.05)$. However, as shown in Fig. 2b, the activity of these key enzymes in lipolysis was lower in the LPS injected animals. The gene expression of carnitine palmitoyltransferase-1A (CPT-1A), which is the key enzyme in $\beta$-oxidation, was significantly increased in the LPS stimulated group, while the gene expression of uncoupling protein 2 (UCP2) was decreased. The gene expression of $11 \beta$-hydroxysteroid dehydrogenase type 1 $(11 \beta$-HSD1) showed a trend to lower values in the LPS group.

\section{Label-free quantitative proteomics analysis}

Table 1 specifies 47 proteins which showed at least a 2fold change between the two groups. The proteins were

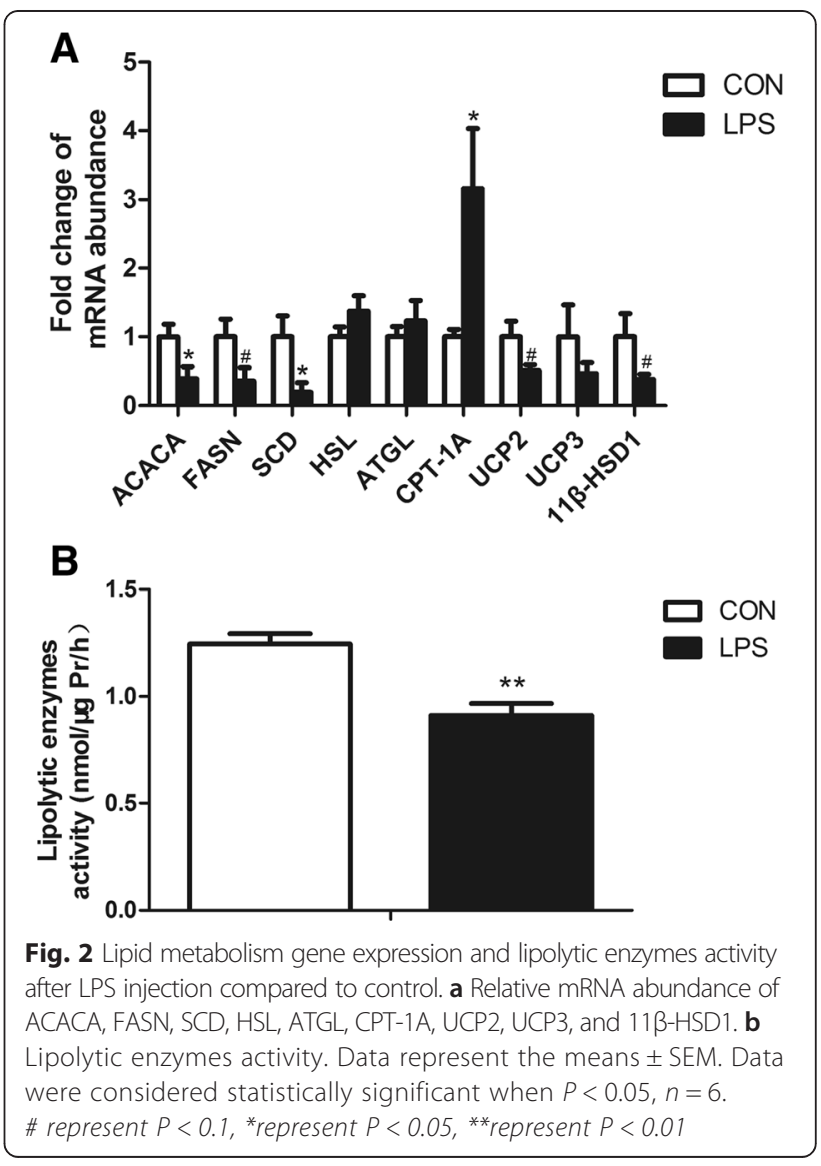


A

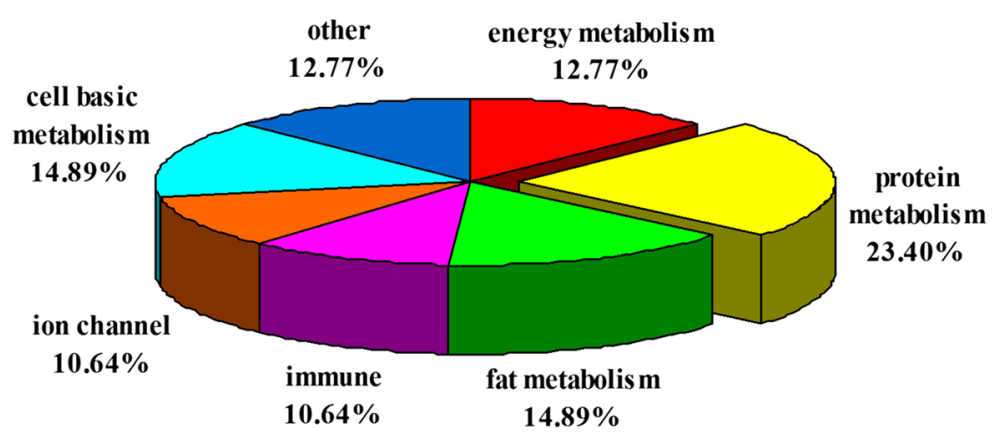

B

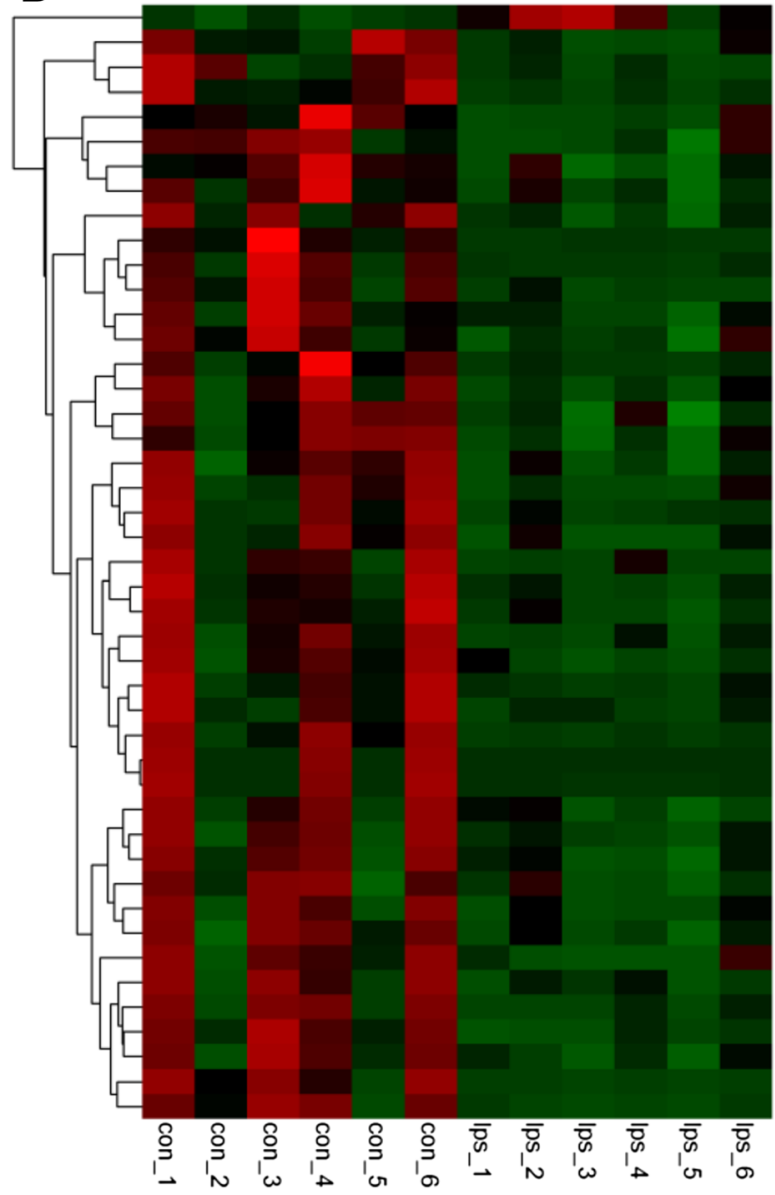

ISG15

KARS

ACSS2

LOC100621569

ELOVL5

RYR1

DNHD1

EIF4H

ILVBL

LOC100737887

FAM213A

TXNL1

LOC100623824

ACOX1

NUCB2

PNP

GNAI3

CTSC

LOC100155139

SRI

RAB2B

RAB2B

LOC 100738149

AKR1C4

LOC100524618

PROSC

CDK5RAP3

HSD11B1

ACSBG2

ALB

DPYSL2;CRMP1

DNM1

SEPT11

LOC396903;LOC100621981

GCKR

PRKAR2A

ILF3;STRBP

RGCC

SNRPD1

MYBBP1A

PSMA4

RTCB

ACTR3

SRSF7:LOC100523801;:SRSF3

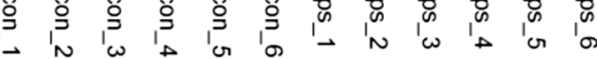

Fig. 3 The classification and heat map of distinct proteins in label-free proteomics analysis. a The classification of distinct proteins. b The heat map of distinct proteins

classified into 7 categories based on their function (Fig. 3a). In Fig. 3b, the heat map of the 47 distinct proteins is shown. The volcano plot and radar chart are shown in Additional file 1: Figure S1 and Additional file 2: Figure S2. The results indicate that cAMPdependent protein kinase type II-alpha regulatory subunit (PRKAR2A) and $\beta$-tubulin (TUBB) were significantly down-regulated following the administration of LPS. The results could be confirmed by western blot analysis (Fig. 4).

\section{mRNA and protein levels of selected adipokines}

As shown in Fig. 5, mRNA abundances of leptin, adiponectin, and zinc- $\alpha 2$-glycoprotein (ZAG) were not different between control and LPS group. Furthermore, the protein content of leptin remained unchanged after LPS 
Table 1 Regulated proteins after LPS injection identified with label-free proteomics analysis

\begin{tabular}{|c|c|c|c|c|}
\hline Number & Name & Gene symbol & Protein Name & Difference \\
\hline 1 & C1PIG4;P05207 & PRKAR2A & $\begin{array}{l}\text { CAMP-dependent protein kinase type II-alpha regulatory } \\
\text { subunit }\end{array}$ & down \\
\hline 2 & F1RGP1 & MYBBP1A & Uncharacterized protein & down \\
\hline 3 & F1RI43;P16960 & RYR1 & Ryanodine receptor 1 & down \\
\hline 4 & F1RJ89 & RGCC & Uncharacterized protein & down \\
\hline 5 & F1RLG5 & REEP5 & Uncharacterized protein & down \\
\hline 6 & F1RMP2 & DNHD1 & Uncharacterized protein & down \\
\hline 7 & F1RSP5 & LOC100524618 & Uncharacterized protein & down \\
\hline 8 & F1RUN2;P08835;CON_P02768-1 & $A L B$ & Serum albumin & down \\
\hline 9 & F1RVZ1 & ACOX1 & Uncharacterized protein & down \\
\hline 10 & F1RWH6 & CDK5RAP3 & Uncharacterized protein & down \\
\hline 11 & F1RX84 & PROSC & Uncharacterized protein & down \\
\hline 12 & F1RYS5 & SEPT11 & Uncharacterized protein & down \\
\hline 13 & F1SOA2 & LOC 100737887 & Peptidyl-prolyl cis-trans isomerase & down \\
\hline 14 & F1S1X9 & TXNL1 & Uncharacterized protein & down \\
\hline 15 & F1S340 & SRI & Uncharacterized protein & down \\
\hline 16 & F1S458 & KARS & Lysine-tRNA ligase & down \\
\hline 17 & F1S4Y0 & ACSS2 & Uncharacterized protein & down \\
\hline 18 & $\mathrm{~F} 1 \mathrm{~S} 8 \mathrm{H} 8$ & PNP & Uncharacterized protein & down \\
\hline 19 & F1S8J6 & RAB2B & Uncharacterized protein & down \\
\hline 20 & F1S9A4 & NUCB2 & Uncharacterized protein & down \\
\hline 21 & F159C9 & LOC100155139 & Proteasome subunit beta type & down \\
\hline 22 & F1SAN6 & ILVBL & Uncharacterized protein & down \\
\hline 23 & F1SBT8 & ACSBG2 & Uncharacterized protein & down \\
\hline 24 & F1SEQ7 & FAM213A & Uncharacterized protein & down \\
\hline 25 & F1SF47 & HSD11B1 & Uncharacterized protein & down \\
\hline 26 & F1SNL7;13LV33 & LOC100621569 & Uncharacterized protein & down \\
\hline 27 & F1STR1 & CTSC & Uncharacterized protein & down \\
\hline 28 & $F 2 Z 528$ & PSMA4 & Proteasome subunit alpha type & down \\
\hline 29 & F2Z5D2 & ACTR3 & Uncharacterized protein & down \\
\hline 30 & F2Z5G9 & SNRPD1 & Uncharacterized protein & down \\
\hline 31 & |3L594;|3LRD5 & ElF4H & Uncharacterized protein & down \\
\hline 32 & I3L5B3;F1SSA6 & $\begin{array}{l}\text { LOC100621981/ } \\
\text { MYH10 }\end{array}$ & Uncharacterized protein & down \\
\hline 33 & 13L5C8 & LOC100623824 & Uncharacterized protein & down \\
\hline 34 & |3L883 & GCKR & Uncharacterized protein & down \\
\hline 35 & |3L8P7 & LOC100738149 & Uncharacterized protein & down \\
\hline 36 & I3LAE9;F1RY92;F1S4R5 & $\begin{array}{l}\text { LOC100523801/ } \\
\text { SRSF3/SRSF7 }\end{array}$ & Uncharacterized protein & down \\
\hline 37 & I3LCZ7;F1RRW8 & N/A/DNM1 & Uncharacterized protein & down \\
\hline 38 & |3LJE2;|3LN38 & DPYSL2/CRMP1 & Uncharacterized protein & down \\
\hline 39 & I3LM05 & N/A & Uncharacterized protein & down \\
\hline 40 & |3LR71 & ELOVL5 & Elongation of very long chain fatty acids protein & down \\
\hline 41 & I3LU39 & ISG15 & Uncharacterized protein & up \\
\hline 42 & K7GQX0;F1SKU5;K7GM70;K7GL83;F1S585;K7GP99 & ILF3/STRBP & Uncharacterized protein & down \\
\hline
\end{tabular}


Table 1 Regulated proteins after LPS injection identified with label-free proteomics analysis (Continued)

\begin{tabular}{lllll}
\hline 43 & Q06AS8 & GNAI3 & GBAK & down \\
44 & Q19PY3;F2Z5V0 & RTCB & tRNA-splicing ligase RtcB homolog & down \\
45 & Q2TJA5 & AKR1C4 & Aldo-keto reductase & down \\
46 & Q767L7 & TUBB & Tubulin beta chain & down \\
47 & Q7YQ94;P15981 & SLA-DQA1/N/A & $\begin{array}{l}\text { MHC class II antigen/SLA class II histocompatibility } \\
\text { antigen, DQ haplotype D alpha chain }\end{array}$ \\
\hline
\end{tabular}

treatment. However, the protein levels of adiponectin and ZAG were significantly increased in the LPS group.

\section{Discussion}

Research on inflammation in human and animals usually focuses on immune system, lung, and kidney etc. which are always regarded as targets for drugs to alleviate the inflammation and recover the health [16-22]. Although WAT has already been recognized as a highly active endocrine organ, its response to inflammation is still unclear. Therefore, this study was conducted to investigate changes of lipid metabolism and proteome of adipose tissue after LPS stimulated inflammation in growing pigs. Recent studies have shown that LPS can induce a systemic inflammation [23]. In recognition of the bacterial LPS by host animals and humans, pattern recognition receptors such as toll-like receptors play a critical role in the innate immune system [24]. Ajuwon et al. demonstrated that LPS could induce NF-kB p65 nuclear translocation and increased the expression of IL-6 and IL-15 in pig adipocytes [25]. Our results accordingly showed that LPS activated the TLR pathway, upregulated the expression of pro-inflammatory factors, and eventually resulted in the inflammation of adipose tissue.

It is well known that the metabolic status of WAT itself plays an important role in the process of storing energy. Lipogenesis and lipolysis are two most basic and important processes in lipometabolism of WAT. Key enzymes in the processes of lipogenesis are, among others, ACACA, FASN, and SCD. Furthermore, HSL and ATGL both play an important role in lipolysis [26]. In our study, the gene expression of ACACA, FASN, and SCD was decreased and the activity of the key enzymes of lipolysis (mainly HSL and ATGL) was also depressed after LPS challenge. The results suggest that the acute inflammation, which LPS caused, could suppress metabolic activity in adipose tissue. CPT- 1 initiates the translocation of long chain fatty acids across the mitochondrial membranes for beta-oxidation [27, 28]. The uncoupling protein family is a mitochondrial anion carrier family and plays an important role in the biological traits of animal body weight, basal metabolic rate, and energy conversion [29]. After LPS stimulation, although the expression of CPT-1A increased significantly, UCP2 and UCP3 expression was decreased. This result demonstrated that energy expenditure is low in adipose tissue in the condition of acute inflammation. The results proved the effect of LPS on the suppression of metabolic activity.

Our results demonstrated that the expression of a variety of lipid metabolism genes significantly changed after LPS stimulation. Therefore, we employed label-free proteomics analysis to investigate protein changes in WAT. All the distinct proteins were shown in the volcano plot and they were obviously separated from the other proteins. In the radar chart, we can clearly see the extent of change for each distinct protein. According to the results of proteome, from all detected differentially expressed proteins, $23.4 \%$ were related to protein metabolism, $14.9 \%$ to fat metabolism, and $12.8 \%$ to energy metabolism. In general, $51.1 \%$ of the detected proteins were metabolism-related. Based on the results of this study, it is obvious that metabolism in white adipose tissue was seriously affected by LPS stimulation, particularly protein metabolism. These results may help to better understand the relationship between the inflammation and the development of metabolic disorders in white adipose tissue. The proteome data showed that the expressions of acyl-CoA synthetase short-chain family member 2 (ACSS2), acyl-CoA synthetase bubblegum family member 2 (ACSBG2) and ELOVL fatty acid elongase 5 (ELOVL5) were all decreased after LPS stimulation. These three proteins are associated with lipogenesis [30-32]. It is well-known that LPS influences immune response [33]. Accordingly, our results revealed $10.6 \%$ of the regulated proteins were immune-related. It is very interesting to note that the proteins involved in ion channel were also influenced and they account for $10.6 \%$ of regulated proteins. Among the 47 proteins that were identified, the levels of only 1 protein increased, whereas the levels of the remaining 46 proteins decreased significantly following LPS administration. Previous studies have demonstrated that total protein synthesis is reduced in response to adverse conditions, which relieves the burden imposed on the protein quality control system [34]. Additionally, the pausing of ribosomal elongation may be involved [35]. Their results may partly explain why adipose tissue protein decreased in the present study.

Among these detected proteins, $11 \beta$-HSD1 is a key enzyme which can convert inactive glucocorticoid into 


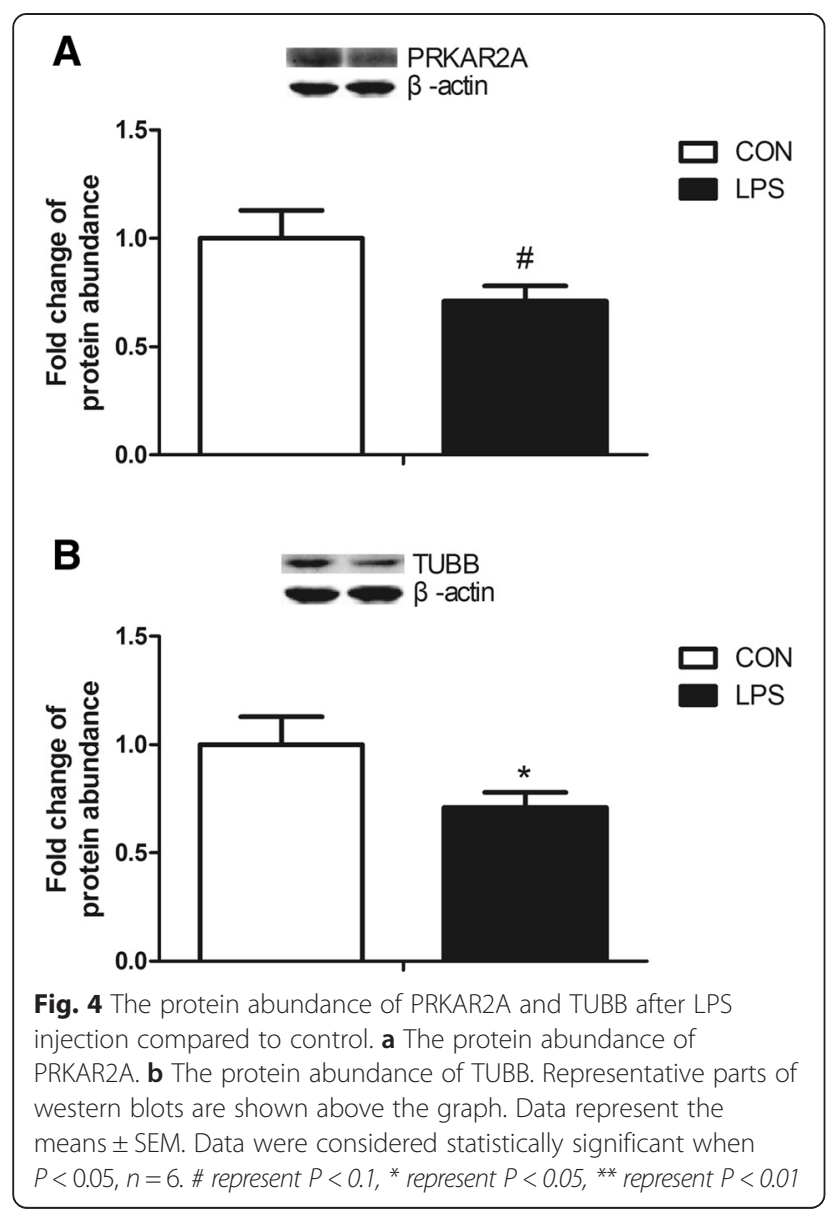

bioactive forms [36]. Moreover, it is regarded as an important amplifier of glucocorticoid activity in peripheral tissues [37]. Several studies have demonstrated that 11 $\beta$-HSD1 is a powerful regulator in modulating WAT metabolism and function [38]. Our results indicated a trend to decreased mRNA expression of $11 \beta-H S D 1$ in the LPS group and also significantly decreased protein expression. In all eukaryotic cells, microtubules, which are integral components of the cytoskeleton, are highly dynamic long filamentous structures which play a key role in some cellular processes, such as cell division, cell migration and support of cell shape and polarity [39]. Microtubules are protein polymers in the form of hollow cylindrical filaments, composed of $\alpha$ - and $\beta$ - tubulin heterodimers $[40,41]$. As we all know, $\beta$-tubulin is very stable in most cases, therefore, it is often used as reference gene. However in this study, we found the expression of $\beta$-tubulin obviously decreased after LPS stimulation according to the analysis of proteome. Chakravortty et al. reported that LPS can cause the disorganization of actin, tubulin and vimentin in bovine aortic endothelial cells [42], which is in concordance with our result. It is well-known that the intracellular target of cAMP is the cAMP-dependent protein kinase (PKA). The inactive PKA holoenzyme is a tetramer consisting of two regulatory (R) and two catalytic $(C)$ subunits; and PRKAR2A is cAMP-dependent protein kinase type II-alpha regulatory subunit [43]. Our results of proteome analysis and verified by western blot revealed that the protein expression of PRKAR2A was extremely decreased after LPS stimulation.

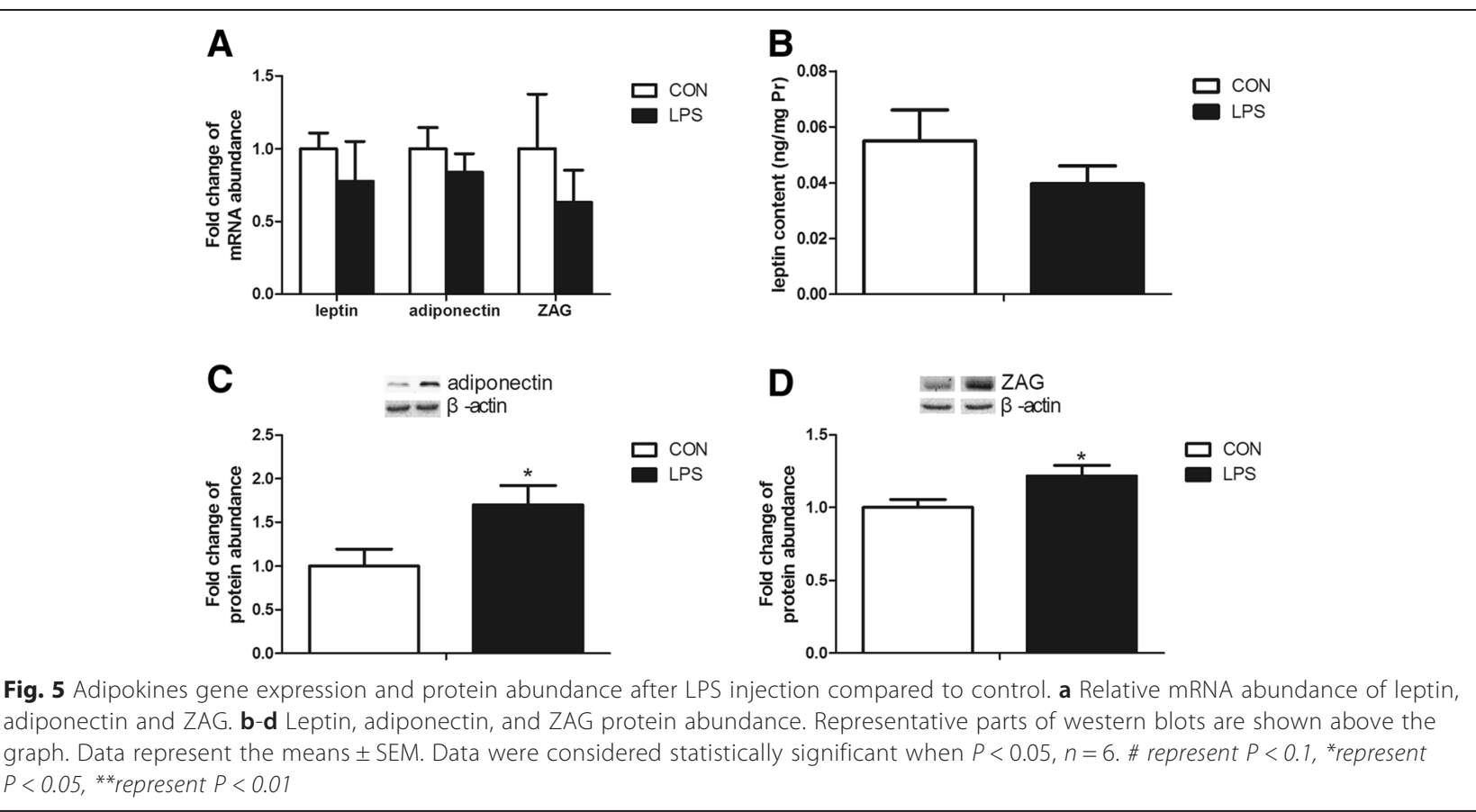


WAT, as an important endocrine organ, plays a vital role on the regulation of inflammation by secreting various adipokines. However, our results of proteome analysis did not indicate that adipokines were regulated. Thus, we selected three of the most studied adipokines, namely leptin, adiponectin and ZAG, to investigate the contribution of WAT to systemic inflammation. The primary role of leptin is control of appetite while it also has an effect on regulating immunity [44, 45]. It can protect $\mathrm{T}$ lymphocytes from apoptosis, regulates T-cell proliferation and influences cytokines production from $\mathrm{T}$ lymphocytes [46]. Gualillo et al. found that inflammation can induce elevation of plasma leptin concentration in rats [47]. Accordingly, Sarraf et al. demonstrated that after administration of Escherichia coli LPS, leptin gene expression and leptin levels were increased [48]. However, our results revealed no difference in leptin expression after LPS stimulation. The reason may be the time of sampling and the dose of LPS stimulation. Adiponectin is best known for its role in the regulation of insulin sensitivity [49]. Recently, scientists demonstrated that adiponectin has the function of anti-inflammation as it can reduce the production and activity of TNF- $\alpha$ and IL6 [50]. Besides, it can also induce the anti-inflammatory cytokines IL-10 and IL-1 receptor antagonist [51-53]. This may contribute to overcome inflammation in an infected organism. In our study, the expression of adiponectin increased under the condition of inflammation. Iwasa et al. found that serum adiponectin levels significantly increased at $6 \mathrm{~h}$ or $24 \mathrm{~h}$ after the injection of LPS [54], which is consistent with our results. ZAG is another adipokine and its overexpression occurs in all kinds of malignant tumors [55], thus, it is now recognized as a cancer marker. However, the biological functions of ZAG are largely unknown. According to the recent researches, ZAG can induce lipolysis by activating hormone-sensitive lipase and its activity is mainly mediated via the $\beta_{3}$ adrenoreceptor with upregulation of the cAMP pathway [56]. Its effect on inflammation is still widely unclear. In 2005, Boat et al. found that LPS can significantly increase the gene expression of ZAG in human adipocytes at the doses of $10 \mathrm{ng} / \mathrm{mL}$ and $100 \mathrm{ng} / \mathrm{mL}$ [57]. In the present study we found ZAG protein expression increased after LPS stimulation suggesting an association with inflammation of adipose tissue.

\section{Conclusion}

LPS injection caused acute inflammation response in white adipose tissue. Most of lipid metabolism related genes were significantly influenced and 47 proteins demonstrated 2 -fold changes in white adipose tissue in the condition of acute inflammation. Simultaneously, two adipokines, adiponectin and ZAG protein content were significantly increased. The results provide new clues to understand the adipose dysfunction during inflammation.

\section{Materials and methods \\ Ethics statement}

The experiment was conducted following the guidelines of Animal Ethics Committee at Nanjing Agricultural University, China. The euthanasia and sampling procedures complied with the "Guidelines on Ethical Treatment of Experimental Animals" (2006) No. 398 set by the Ministry of Science and Technology, China and "the Regulation regarding the Management and Treatment of Experimental Animals" (2008) No. 45 set by the Jiangsu Provincial People's Government.

\section{Animals and experimental design}

Twelve Duroc $\times($ Landrace $\times$ Large White) male pigs from Huaian commercial farm of similar age and weight $(12 \pm 0.5 \mathrm{~kg})$ were used in this experiment. The pigs were randomly divided into a control group and a lipopolysaccharide (LPS) injected group. They were fed thrice a day with a commercial pig diet for growing pigs. Water was available ad libitum. This study was conducted at the Jiangsu Academy of Agricultural Sciences.

Before starting the experiment, all the pigs were allowed to adapt to the environment for one week. After adaptation, the pigs of the LPS group $(n=6)$ were injected intramuscularly with LPS (E. coli serotype, Sigma Aldrich Ireland, Ltd) at a dose of $15 \mu \mathrm{g} / \mathrm{kg}$ body weight. The remaining pigs $(n=6)$ received an equivalent volume of physiological saline at the same time. Six hours after LPS injection, the pigs were sacrificed by exsanguination. Back fat samples were collected and frozen in liquid nitrogen, finally stored at $-70{ }^{\circ} \mathrm{C}$.

\section{RNA isolation, cDNA synthesis and real-time PCR}

Total RNA was extracted from back fat samples with Total RNA Isolation Reagent (3101-100, Shanghai Pufei Biotech). Quantity of the RNA was measured by NanoDrop ND-1000 spectrophotometer (Thermo, USA). The ratios of absorption (260/280 nm) of all samples were between 1.8 and 2.0. Aliquots of RNA samples were subjected to electrophoresis using a $1.4 \%$ agarose-formaldehyde gel to verify RNA integrity. Two micrograms of total RNA were treated with RNase-free DNase (M6101, Promega, USA) and reverse-transcribed according to the manufacturer's instructions. Two microliters of diluted cDNA (1:20, vol/vol) were used for real-time PCR which was detected in Mx3000P (Stratagene, USA). All the primers were designed with the software "Primer Premier 6" and then blasted in NCBI. Peptidylprolyl isomerase A (PPIA), which is not affected by the experimental factors (LPS), was chosen as the reference gene. All the primers chosen to study the expression of genes related 
Table 2 Primer sequences for real-time PCR amplification

\begin{tabular}{|c|c|c|}
\hline Target genes & Reference/GenBank accession & Primer sequences \\
\hline TLR2 & NM_213761.1 & F: GACACCGCCATCCTCATTCT R: CTTCCCGCTGCGTCTCAT \\
\hline TLR4 & AB188301.2 & F: TCTACATCAAGTGCCCCTAC R: TAAATTCTCCCAAAACCAAC \\
\hline NF-KB p65 & KC316023.1 & F: GGGGACTACGACCTGAATGC R: CACGGTTGTCAAAGATGGG \\
\hline TNF-a & X57321.1 & F: CCACGCTCTTCTGCCTACTGC R: TCGGCTITGACATTGGCTACAA \\
\hline IL-1a & NM_214029.1 & F: TACTGACTATGGCTACCAA R: ATTCCAGCTGCTATTGTG \\
\hline IL-1 $\beta$ & AY291592.1 & F: CCGCCAAGATATAACTGAC R: GCAGCAACCATGTACCAA \\
\hline IL-6 & AF518322.1 & F: AATGCTCTTCACCTCTCC R: CACACTTCTCATACTTCTCAC \\
\hline ACACA & NM_001114269.1 & F: GGCCATCAAGGACTTCAACC R: ACGATGTAAGCGCCGAACTT \\
\hline FASN & NM_001099930.1 & F: GTCCTGCTGAAGCCTAACTC R: TCCTTGGAACCGTCTGTG \\
\hline SCD & NM_213781.1 & F: CTACACAACCACCACTACCATCAC R: GCAAACGCCCAGAGCAAGG \\
\hline HSL & HM591297.1 & F: ACCCTCGGCTGTCAACTTCTT R: TCCTCCTTGGTGCTAATCTCGT \\
\hline ATGL & EU373817.1 & F: ACCTGTCCAACCTGCTGC R: GCCTGTCTGCTCCTTTATCCA \\
\hline CPT-1A & NM_001129805.1 & F: ACAACGAGGTCTTCCGAT R: AACGCAAAACCACCAAACCC \\
\hline UCP2 & NM_214289.1 & F: GACGCCTACAAGACCATC R: CTCAGCACAGTTGACAATG \\
\hline UCP3 & NM_214049.1 & F: GACGATGGATGCCTACAG R: CACCTTCTCCTTGATGACA \\
\hline $11 \beta-H S D 1$ & NM_214248.1 & F: CCATGCTGAAGCAGAGCAAC R: AAGAACCCGTCCAGAGCAAA \\
\hline ZAG & XM_003124307.2 & F: GCAGCCGTGAACACCAAGC R: GGTACCTCCGCAGCATCCC \\
\hline adiponectin & EF601160.1 & F: CCGTTCAGCATTCAGTGT R: CAGCCTTGTCCTTCTTGTA \\
\hline leptin & NM_213840.1 & F: CATCCATTGTTCGCTGTG R: CTGTCCTCTCCATTAGTCTC \\
\hline PPIA & JX523418.1 & F:GACTGAGTGGTTGGATGG R:TGATCTTCTTGCTGGTCTT \\
\hline
\end{tabular}

TLR2 toll-like receptor 2, NF-KB p65 nuclear factor-kappa B p65, TNF- $a$ tumor necrosis factor-a, IL-1a interleukin-1a, ACACA acetyl-CoA carboxylase alpha, FASN fatty acid synthase, $S C D$ stearoyl-CoA desaturase, HSL hormone-sensitive lipase, $A T G L$ adipose triglyceride lipase, $C P T-1 A$ carnitine palmitoyltransferase $1 \mathrm{~A}, U C P 2$ uncoupling protein 2,11ß-HSD1 hydroxysteroid (11-beta) dehydrogenase 1, ZAG zinc-a2-glycoprotein, PPIA Peptidylprolyl isomerase A

to immune response and lipid metabolism, as listed in Table 2, were synthesized by Generay (Shanghai, China). The method of $2^{-\Delta \Delta C t}$ was used to analyze the real-time PCR results and gene mRNA levels were expressed as the fold change relative to the mean value of control group (Livak and Schmittgen, 2001).

\section{Adipose tissue preparation, total protein extraction and western blot}

Frozen back fat samples (400 mg each) were minced and homogenized in $2 \mathrm{~mL}$ each of ice-cold homogenization buffer RIPA containing the protease inhibitor cocktail (Complete EDTA-free, Roche, Penzberg, Germany). Protein concentration was determined using a BCA Protein Assay kit (Pierce, Rockford, IL, USA). Forty micrograms of protein extract from each sample were then loaded onto $7.5 \%$ SDS-PAGE gels and the separated proteins were transferred onto nitrocellulose membranes (Bio Trace, Pall Co, USA). After transfer, membranes were blocked for $2 \mathrm{~h}$ at room temperature in blocking buffer and then membranes were incubated with the primary antibodies, in dilution buffer over night at $4{ }^{\circ} \mathrm{C}$. After several washes in tris-buffered-saline with Tween (TBST), membranes were incubated with the secondary antibodies in dilution buffer for $2 \mathrm{~h}$ at room temperature. After several washes, bands were visualized by enhanced chemiluminescence substrate (Super Signal West Pico, Pierce, USA), and the signals were recorded by an imaging system (Bio-Rad, USA), and analyzed with Quantity One software (Bio-Rad, USA).

The primary antibodies were against adiponectin (Bioworld, BS2833, 1:1000), zinc- $\alpha 2$-glycoprotein (Santa Cruz, sc-21721, 1:500), TUBB (Bioworld, BS1482MH, 1:10000), and PRKAR2A (Bioworld, BS1929, 1:1000). The secondary antibodies were goat anti-rabbit horseradish peroxidase (HRP) antibody (Bioworld, BS13278, 1:10000) and goat anti-mouse HRP antibody (Bioworld, BS124789, 1:10000).

\section{Lipolytic enzymes activity assay}

A modification of the procedure of Zhang et al. was used to extract and assay the lipolytic enzymes [58]. Briefly, $500 \mathrm{mg}$ of frozen adipose tissue in $1 \mathrm{ml}$ of homogenization buffer $\left(0.1 \mathrm{M} \mathrm{K}{ }^{+}\right.$-PBS containing $1 \mathrm{mM} \mathrm{MgCl}_{2}, 1 \mathrm{mM}$ DTT and $1 \mathrm{mM}$ EDTA) was homogenized on ice for $30 \mathrm{~min}$, and then centrifuged at $12,000 \times \mathrm{g}$ at $4{ }^{\circ} \mathrm{C}$. The protein content of supernatants was determined using a BCA Protein Assay kit (Pierce, Rockford, IL, USA). Triolein 
without glycerin was used as substrate which can be hydrolyzed to glycerol by lipolytic enzymes. The supernatant together with prepared triolein were incubated for $1 \mathrm{~h}$ at $37{ }^{\circ} \mathrm{C}$. The lipolytic enzymes in supernatant activate the lypolytic degradation of the triolein emulsion. The released glycerol was determined using a commercial kit (Applygen, China). Standard curves were constructed with pure enzymes to calculate the activities of the enzymes. All samples were measured in duplicate at appropriate dilutions.

\section{Radioimmunoassay}

The content of leptin in back fat was measured using a commercial multispecies radioimmunoassay (RIA) kit (Beijing North Institute of Biotechnology, Beijing, China), according to the manufacturers' instructions. A $200 \mathrm{mg}$ frozen back fat sample was minced and homogenized in $1 \mathrm{~mL}$ phosphate buffered saline (PBS). Then, the homogenate was freeze-dried and redissolved in $200 \mu \mathrm{L}$ PBS. Finally, leptin content was measured in this $200 \mu \mathrm{L}$ solution.

\section{Label-free quantitative proteomics analysis}

Another $200 \mathrm{mg}$ back fat sample was weighed and the total protein was extracted using $1 \mathrm{~mL}$ ice-cold homogenization buffer RIPA containing the protease inhibitor cocktail (Complete EDTA-free, Roche, Penzberg, Germany). The same quality $(250 \mu \mathrm{g})$ for each sample was used for the proteomics analysis. Next, the total protein was digested according to the method of filter-aided sample preparation (FASP) which combines the advantages of in-gel and insolution digestion for mass spectrometry-based proteomics [59]. Then, LC-MS/MS method was used to quantify the peptide fragments [60]. This experiment was conducted in College of Life Science in Nanjing Agricultural University. Finally, the results were analyzed by employing the software MaxQuant [61]. The proteins which exhibited a change of at least 2-fold between groups were selected. The data analysis of the proteome was conducted by BioNovoGene. By using the software MaxQuant, the number of proteins identified for each animal in the control group was 817, $610,616,679,575$, and 829 , respectively; and the number of proteins identified for each animal in the LPS group was $446,712,549,756,533$, and 744, respectively. Then, according to the $P$-value $<0.05$ and fold change $>2$ after $T$ test, we identified 47 regulated proteins.

\section{Statistical analysis}

All data are presented as the means \pm standard errors. The statistical analyses were performed using the Statistical Program for Social Sciences (SPSS) software, version 20.0, for Windows. The differences were tested via an analysis of variance (ANOVA), and a t-test was used for independent samples. Differences with $\mathrm{P}$ values $<0.05$ were considered statistically significant.

\section{Consent}

Written informed consent was obtained from the patient for the publication of this report and any accompanying images.

\section{Additional files}

Additional file 1: Figure S1. The volcano plot of distinct proteins in label-free proteomics analysis.

Additional file 2: Figure S2. The radar chart of distinct proteins in label-free proteomics analysis.

\section{Abbreviations}

WAT: White adipose tissue; LPS: Lipopolysaccharide; TLR2: Toll-like receptor 2; NF-kB p65: Nuclear factor-kappa B p65; TNF-a: Tumor necrosis factor-a; IL-1a: Interleukin-1a; ACACA: Acetyl-CoA carboxylase alpha; FASN: Fatty acid synthase; SCD: Stearoyl-CoA desaturase; HSL: Hormone-sensitive lipase; ATGL: Adipose triglyceride lipase; CPT-1A: Carnitine palmitoyltransferase 1A; UCP2: Uncoupling protein 2; 11ß-HSD1: Hydroxysteroid (11-beta) dehydrogenase 1; ACSS2: Acyl-CoA synthetase short-chain family member 2; ACSBG2: Acyl-COA synthetase bubblegum family member 2; ELOVL5: ELOVL fatty acid elongase 5; PRKAR2A: CAMP-dependent protein kinase type II-alpha regulatory subunit; TUBB: $\beta$-tubulin; ZAG: Zinc-a2-glycoprotein;

PPIA: Peptidylprolyl isomerase A.

\section{Competing interests}

The authors declare that they have no competing interests.

\section{Authors' contributions}

The authors' responsibilities were as follows: JG, RQZ and XJY designed research; JG conducted research; JG analyzed data; ZQL, HLS, YPH contributed reagents, materials and analysis tools; JG prepared the first draft of the paper that was revised by XJY; EA and XJY revised the paper again

$J G$ had primary responsibility for final content. All authors read and approved the final manuscript.

\section{Acknowledgements}

This study was supported by the National Basic Research Program of China (2012CB124703), the Special Fund for Agro-scientific Research in the Public Interest (201003011), the Program for New Century Excellent Talents in University (NCET-12-0889) and the Priority Academic Program Development of Jiangsu Higher Education Institutions.

\section{Author details}

1 Key Laboratory of Animal Physiology \& Biochemistry, Nanjing Agricultural University, Nanjing 210095, PR China. Institute of Muscle Biology and Growth, Leibniz-Institute for Farm Animal Biology (FBN), Dummerstorf, Germany.

Received: 11 February 2015 Accepted: 26 June 2015

Published online: 08 July 2015

\section{References}

1. Mohamed-Ali V, Pinkney JH, Coppack SW. Adipose tissue as an endocrine and paracrine organ. Int J Obes (Lond). 1998;22:1145-58.

2. Trayhurn P, Beattie JH. Physiological role of adipose tissue: white adipose tissue as an endocrine and secretory organ. Proc Nutr Soc. 2001;60:329-39.

3. Zhang LJ, Guerrero-Juarez CF, Hata T, Bapat SP, Ramos R, Plikus MV, et al. Dermal adipocytes protect against invasive Staphylococcus aureus skin infection. Science. 2015:347:67-71.

4. Vieira-Potter VJ. Inflammation and macrophage modulation in adipose tissues. Cell Microbiol. 2014;16:1484-92.

5. Meijer K, de Vries M, Al-Lahham S, Bruinenberg M, Weening D, Dijkstra M, et al. Human Primary Adipocytes Exhibit Immune Cell Function: Adipocytes Prime Inflammation Independent of Macrophages. Plos One. 2011;6:e17154.

6. Kohn FR, Kung AHC. Role of endotoxin in acute-inflammation induced by gram-negative bacteria - specific-inhibition of lipopolysaccharide-mediated 
responses with an amino-terminal fragment of bactericidal/permeabilityincreasing protein. Infect Immun. 1995;63:333-9.

7. Izaola O, De Luis D, Sajoux I, Domingo JC, Vidal M. Inflammation and obesity (lipoinflammation). Nutr Hosp. 2015;31:2352-8.

8. Sedy J, Bekiaris V, Ware CF. Tumor Necrosis Factor Superfamily in Innate Immunity and Inflammation. Cold Spring Harb Perspect Biol. 2014;7:a016279.

9. Szalowska E, Dijkstra M, Elferink MG, Weening D, de Vries M, Bruinenberg M, et al. Comparative analysis of the human hepatic and adipose tissue transcriptomes during LPS-induced inflammation leads to the identification of differential biological pathways and candidate biomarkers. BMC Med Genomics. 2011:4:71.

10. Osto M, Zini E, Franchini M, Wolfrum C, Guscetti F, Hafner M, et al. Subacute endotoxemia induces adipose inflammation and changes in lipid and lipoprotein metabolism in cats. Endocrinology. 2011;152:804-15.

11. Shah R, Lu Y, Hinkle CC, McGillicuddy FC, Kim R, Hannenhalli S, et al. Gene profiling of human adipose tissue during evoked inflammation in vivo. Diabetes. 2009;58:2211-9.

12. Vatier C, Kadiri S, Muscat A, Chapron C, Capeau J, Antoine B. Visceral and subcutaneous adipose tissue from lean women respond differently to lipopolysaccharide-induced alteration of inflammation and glyceroneogenesis. Nutr Diabetes. 2012;2:e51.

13. Hou X, Zhang J, Ahmad H, Zhang H, Xu Z, Wang T. Evaluation of antioxidant activities of ampelopsin and its protective effect in lipopolysaccharide-induced oxidative stress piglets. PLoS One. 2014;9:e108314.

14. Westphal M, Stubbe $H$, Sielenkamper AW, Borgulya R, Van Aken H, Ball C, et al. Terlipressin dose response in healthy and endotoxemic sheep: impact on cardiopulmonary performance and global oxygen transport. Intensive Care Med. 2003;29:301-8.

15. Megger DA, Bracht T, Meyer HE, Sitek B. Label-free quantification in clinical proteomics. Biochim Biophys Acta. 2013;1834:1581-90.

16. Cheng HS, Njock MS, Khyzha N, Dang LT, Fish JE. Noncoding RNAs regulate NF-kappaB signaling to modulate blood vessel inflammation. Front Genet. 2014:5:422.

17. Fan L, Wang T, Chang L, Song Y, Wu Y, Ma D. Systemic inflammation induces a profound long term brain cell injury in rats. Acta Neurobiol Exp (Wars). 2014;74:298-306.

18. Wei Y, Asbell PA. The core mechanism of dry eye disease is inflammation. Eye Contact Lens-Sci Clin Pract. 2014;40:248-56.

19. Jensen ME, Gibson PG, Collins CE, Wood LG. Airway and systemic inflammation in obese children with asthma. Eur Respir J. 2013;42:1012-9.

20. Passino C, Barison A, Vergaro G, Gabutti A, Borrelli C, Emdin M, et al. Markers of fibrosis, inflammation, and remodeling pathways in heart failure. Clin Chim Acta. 2015;443:29-38.

21. Lopez B, Maisonet TM, Londhe VA. Alveolar NF-kappaB signaling regulates endotoxin-induced lung inflammation. Exp Lung Res. 2015;41:103-14.

22. Garcia-Garcia PM, Getino-Melian MA, Dominguez-Pimentel V, NavarroGonzalez JF. Inflammation in diabetic kidney disease. World J Diabetes. 2014:5:431-43.

23. Rietschel ET, Schletter J, Weidemann B, El-Samalouti V, Mattern T, Zähringer U, et al. Lipopolysaccharide and peptidoglycan: CD14-dependent bacterial inducers of inflammation. Microb Drug Resist. 1998;4:37-44.

24. Takeda K, Akira S. TLR signaling pathways. Semin Immunol. 2004;16:3-9.

25. Ajuwon KM, Jacobi SK, Kuske JL, Spurlock ME. Interleukin-6 and interleukin-15 are selectively regulated by lipopolysaccharide and interferon-gamma in primary pig adipocytes. Am J Physiol Regul Integr Comp Physiol. 2004;286:R547-53.

26. Reue K. A thematic review series: lipid droplet storage and metabolism: from yeast to man. J Lipid Res. 2011;52:1865-8.

27. McGarry JD, Brown NF. The mitochondrial carnitine palmitoyltransferase system - From concept to molecular analysis. Eur J Biochem. 1997;244:1-14.

28. Song S, Attia RR, Connaughton S, Niesen MI, Ness GC, Elam MB, et al. Peroxisome proliferator activated receptor alpha (PPARalpha) and PPAR gamma coactivator (PGC-1alpha) induce carnitine palmitoyltransferase IA (CPT-1A) via independent gene elements. Mol Cell Endocrinol. 2010;325:54-63.

29. Li H, Li Y, Zhao X, Li N, Wu C. Structure and nucleotide polymorphisms in pig uncoupling protein 2 and 3 genes. Anim Biotechnol. 2005;16:209-20.

30. Sone $H$, Shimano H, Sakakura Y, Inoue N, Amemiya-Kudo M, Yahagi N, et al. Acetyl-coenzyme A synthetase is a lipogenic enzyme controlled by SREBP-1 and energy status. Am J Physiol Endocrinol Metab. 2002;282:E222-30
31. Pei $Z$, Jia Z, Watkins PA. The second member of the human and murine bubblegum family is a testis- and brainstem-specific acyl-CoA synthetase. J Biol Chem. 2006;281:6632-41.

32. Tripathy S, Lytle KA, Stevens RD, Bain JR, Newgard CB, Greenberg AS, et al. Fatty acid elongase-5 (Elovl5) regulates hepatic triglyceride catabolism in obese C57BL/6 J mice. J Lipid Res. 2014;55:1448-64.

33. Maliszewski CR. CD14 and immune response to lipopolysaccharide. Science. 1991;252:1321-2

34. Sherman MY, Qian SB. Less is more: improving proteostasis by translation slow down. Trends Biochem Sci. 2013:38:585-91.

35. Liu BT, Han Y, Qian SB. Cotranslational response to proteotoxic stress by elongation pausing of ribosomes. Mol Cell. 2013;49:453-63.

36. Liu J, Kong X, Wang L, Qi H, Di W, Zhang X, et al. Essential roles of 11 beta-HSD1 in regulating brown adipocyte function. J Mol Endocrinol. 2013;50:103-13.

37. Seckl JR. 11 beta-hydroxysteroid dehydrogenases: changing glucocorticoid action. Curr Opin Pharmacol. 2004;4:597-602.

38. Bujalska IJ, Kumar S, Hewison M, Stewart PM. Differentiation of adipose stromal cells: the roles of glucocorticoids and 11 beta-hydroxysteroid dehydrogenase. Endocrinology. 1999;140:3188-96.

39. Zhou J, Giannakakou P. Targeting microtubules for cancer chemotherapy. Curr Med Chem Anticancer Agents. 2005;5:65-71.

40. Nogales E, Whittaker M, Milligan RA, Downing KH. High-resolution model of the microtubule. Cell. 1999;96:79-88.

41. Liu YM, Chen HL, Lee HY, Liou JP. Tubulin inhibitors: a patent review. Expert Opin Ther Pat. 2014;24:69-88.

42. Chakravortty D, Koide N, Kato Y, Sugiyama T, Kawai M, Fukada M, et al. Cytoskeletal alterations in lipopolysaccharide-induced bovine vascular endothelial cell injury and its prevention by sodium arsenite. Clin Diagn Lab Immunol. 2000;7:218-25.

43. Tasken K, Naylor SL, Solberg R, Jahnsen T. Mapping of the gene encoding the regulatory subunit RIl alpha of CAMP-dependent protein kinase (locus PRKAR2A) to human chromosome region 3p21.3-p21.2. Genomics. 1998:50:378-81.

44. Fantuzzi $G$, Faggioni R. Leptin in the regulation of immunity, inflammation, and hematopoiesis. J Leukoc Biol. 2000;68:437-46.

45. Sanchez-Margalet V, Martin-Romero C, Santos-Alvarez J, Goberna R, Najib S Gonzalez-Yanes C. Role of leptin as an immunomodulator of blood mononuclear cells: mechanisms of action. Clin Exp Immunol. 2003;133:11-9.

46. Faroogi IS, Matarese G, Lord GM, Keogh JM, Lawrence E, Agwu C, et al. Beneficial effects of leptin on obesity, T cell hyporesponsiveness, and neuroendocrine/metabolic dysfunction of human congenital leptin deficiency. Eur J Clin Invest. 2002;110:1093-103.

47. Gualillo O, Eiras S, Lago F, Dieguez C, Casanueva FF. Elevated serum leptin concentrations induced by experimental acute inflammation. Life Sci. 2000;67:2433-41

48. Sarraf P, Frederich RC, Turner EM, Ma G, Jaskowiak NT, Rivet DJ 3rd, et al. Multiple cytokines and acute inflammation raise mouse leptin levels: Potential role in inflammatory anorexia. J Exp Med. 1997;185:171-5.

49. Beltowski J. Adiponectin and resistin-new hormones of white adipose tissue. Med Sci Monit. 2003;9:RA55-61.

50. Masaki T, Chiba S, Tatsukawa H, Yasuda T, Noguchi H, Seike M, et al. Adiponectin protects LPS-induced liver injury through modulation of TNF-alpha in KK-Ay obese mice. Hepatology. 2004;40:177-84.

51. Kumada M, Kihara S, Ouchi N, Kobayashi H, Okamoto Y, Ohashi K, et al. Adiponectin specifically increased tissue inhibitor of metalloproteinase-1 through interleukin-10 expression in human macrophages. Circulation. 2004:109:2046-9.

52. Wolf AM, Wolf $D$, Rumpold $H$, Enrich $B$, Tilg $H$. Adiponectin induces the anti-inflammatory cytokines IL-10 and IL-1RA in human leukocytes. Biochem Biophys Res Commun. 2004;323:630-5

53. Wulster-Radcliffe MC, Ajuwon KM, Wang JZ, Christian JA, Spurlock ME. Adiponectin differentially regulates cytokines in porcine macrophages. Biochem Biophys Res Commun. 2004:316:924-9.

54. Iwasa T, Matsuzaki T, Matsui S, Munkhzaya M, Tungalagsuvd A, Kawami T, et al. The effects of LPS-induced endotoxemia on the expression of adiponectin and its receptors in female rats. Endocr J. 2014;61:891-900.

55. Hale LP, Price DT, Sanchez LM, Demark-Wahnefried W, Madden JF. Zinc alpha-2-glycoprotein is expressed by malignant prostatic epithelium and may serve as a potential serum marker for prostate cancer. Clin Cancer Res 2001;7:846-53. 
56. Russell ST, Hirai K, Tisdale MJ. Role of beta3-adrenergic receptors in the action of a tumour lipid mobilizing factor. Br J Cancer. 2002;86:424-8.

57. Bao Y, Bing C, Hunter L, Jenkins JR, Wabitsch M, Trayhurn P. Zinc-alpha(2)-glycoprotein, a lipid mobilizing factor, and is expressed and secreted by human (SGBS) adipocytes. Febs Letters. 2005;579:41-7.

58. Zhang TT, Xu C, Zu LX, He JH, Pu SS, Guo XH, et al. The mechanisms of stimulated lipolysis by high concentration of glucose in primary rat adipocytes. Beijing Da Xue Xue Bao. 2008:40:273-9.

59. Wisniewski JR, Zougman A, Nagaraj N, Mann M. Universal sample preparation method for proteome analysis. Nat Methods. 2009;6:359-62.

60. Titulaer MK, de Costa D, Stingl C, Dekker LJ, Sillevis Smitt PA, Luider TM. Label-free peptide profiling of Orbitrap full mass spectra. BMC Res Notes. 2011;4:21.

61. Nie JZ, An L, Miao K, Hou ZC, Yu Y, Tan K, et al. Comparative analysis of dynamic proteomic profiles between in vivo and in vitro produced mouse embryos during postimplantation period. J Proteome Res. 2013;12:3843-56.

\section{Submit your next manuscript to BioMed Central and take full advantage of:}

- Convenient online submission

- Thorough peer review

- No space constraints or color figure charges

- Immediate publication on acceptance

- Inclusion in PubMed, CAS, Scopus and Google Scholar

- Research which is freely available for redistribution 